\title{
EFISIENSI REPRODUKSI KAMBING PERANKAN ETAWA DI LEMBAH GOGONITI FARM DI DESA KEMIRIGEDE KECAMATAN KESAMBEN KABUPATEN BLITAR
}

\author{
Drh. Edya Moelia Lubis, MSi \\ Dosen Program Studi Ilmu Ternak Fakultas Peternakan \\ Universitas Islam Balitar \\ Jl. Majapahit No 04 , Blitar Jawa Timur, Indonesia
}

\begin{abstract}
The purpose of this research is to know the level of reproduction efficiency through Conception Rate (CR), Service per Conception (S / C), Days Open (DO), and Kidding Interval (KI) in Kemirigede Village Kesamben District, Blitar Regency. The usefulness of this research is as a guideline for goat breeders in improving livestock raising management, adding insight on the importance of knowing CR, S / C, DO and KI and as a reference of the breeders for goat breeding especially in reproduction efficiency. The research material was Etawa females 35 female heads. The method used is survey method, while the selection of livestock sample is done by purposive sampling. Data analysis using descriptive analysis. The research results of Etawa Peranakan Goats in Lembah Gogoniti Farm Desa Kemirigede Kesamben Subdistrict of Blitar District showed that CR value was $85 \%$, S / C 2.5 years 1 time, age 3 years 1 time and age 5 years 1.41 times, KI age 2.5 years 6.49 months, age 3 years 6.56 months, age 4 years 6,81 months and age 5 years 7.04 months and DO age 2.5 years 44 days, age 3 years 46.8 days , age 4 years 53.75 days and age 5 years 60.5 days. The conclusions of this study are the RC, $\mathrm{S} / \mathrm{C}, \mathrm{KI}$ and DO values according to the standard (for Conception Rate of at least $60 \%$, Service per Conception 1.0 - 2.0, 9 Months Kidding Interval and 90 Days Open Days). Suggested breeders not only refers to the CR system, but also on the system S / C, KI and DO so that will get optimal results.
\end{abstract}

Keywords: Production Efficiency, Conception Rate, Days Open

\section{Pendahuluan}

Kambing Peranakan Etawa (PE) merupakan ternak kambing lokal yang telah beradaptasi baik dengan kondisi lingkungan di Indonesia. Namun sampai saat ini penyebaran kambing PE ini masih sangat terbatas dengan total populasi sekitar 14 juta ekor, tersebar tidak merata diseluruh wilayah Indonesia dan hanya 57\% dari populasi tersebut ada dipulau jawa dan madura (Direktorat Jendral Peternakan, 2006).

Kambing PE sebagai ternak kambing tipe dwiguna tingkat produktivitasnya masih rendah. Oleh karena itu, upaya peningkatan produktivitasnya perlu dilakukan, salah satunya adalah dengan pendekatan perbaikan manajemen pemeliharaan induk dan anak kambing agar tingkat kematian anak dapat ditekan.

Kambing Peranakan Etawa (PE) merupakan bangsa kambing asli Indonesia yang merupakan hasil persilangan antara Kambing Etawa yang berasal dari India dengan Kambing Kacang yang merupakan bangsa kambing asli Indonesia. Kambing ini dibudidayakan pertama kali oleh masyarakat Kaligesing, Purworejo, Jawa Tengah. Sejak lama kambing PE sudah menyebar ke berbagai wilayah di Indonesia dan mendominasi spesies kambing di Indonesia bagian barat, khususnya Pulau Jawa.

Perkawinan pada kambing dilakukan untuk melanjutkan keturunan dan atau untuk menghasilkan keturunan yang lebih baik sesuai dengan yang diharapkan baik secara kuantitas 
maupun kualitas. Mengawinkan betina yang sedang birahi sebaiknya dicampur dengan pejantan dalam satu kandang dan waktu yang tepat untuk mengawinkan kambing adalah 12-18 jam setelah birahi pertama (Setiawan dan Tanius, 2003).

Dewasa kelamin pada ternak kambing untuk yang jantan adalah pada usia 8 bulan, sedangkan pada kambing betina pada usia 15 bulan. Dengan alasan ini, maka kambing betina dapat mulai di kawinkan untuk pertama kalinya mulai usia 15 bulan. Sedang untuk kambing jantan yang ideal untuk dikawinkan sebagai ternak pemacak adalah setelah mencapai usia di atas 12 bulan (Murtidjo,1993).

Kambing betina mulai dewasa pada umur $6-8$ bulan. Pada usia tersebut kambing sudah bisa dikawinkan. Namun, untuk kambing PE perkawinan pada usia tersebut harus di hindari karena alat reproduksinya belum berkembang sempurna. Sebaiknya masa perkawinannya ditangguhkan hingga umur antara 15 - 18 bulan. Untuk menghindari perkawinan muda usia, pemeliharaan kambing betina dipisahkan sejak usia 5 bulan. Di dalam kandang maupun di tempat pengembalaan, kambing betina sebaiknya di pisahkan dari kambing jantan. Kandang kambing jantan sebaiknya cukup luas sehingga kambing dapat bergerak leluasa, kuat, dan aktif (Sarwono, 1990).

Perkawinan kambing jantan dan betina harus di atur agar tidak terlalu lelah. Satu ekor pejantan dapat mengawini 20 - 25 ekor betina dan dalam sehari dapat melakukan perkawinan 4 -5 kali sebanyak 2 - 3 hari/minggu. Masa birahi untuk kambing betina berlangsung selama $24-28$ jam dan akan timbul berselang $18-21$ hari.

Salah satu pedoman penentuan efisiensi reproduksi dengan cepat ialah suatu cara penentuan kebuntingan secara mudah dan objektif segera setelah konsepsi. Setiap ternak kambing, misalnya memerlukan pemeriksaan yang teliti dan memakan waktu oleh seorang dokter hewan untuk menentukan kebuntingan secara rektal. Kemungkinan diagnosa yang tepat hanya dapat terjadi sesudah melewati beberapa minggu dari saat perkawinan dan kemungkinan tersebut meninggi dengan bertambahnya waktu. Suatu diagnosa palpasi rektal yang positif mungkin hanya berlaku pada saat itu karena banyak faktor, terutama penyakit-penyakit yang menyebabkan abortus, dapat mengganggu jalannya kebuntingan yang normal. Pedoman yang dapat digunakan untuk keberhasilan perkawinan hanyalah kelahiran anak yang sehat. Akan tetapi, untuk menunggu sampai terjadinya kelahiran akan terlampau lambat dalam penentuan kebijaksanaan selanjutnya dalam pelaksanaan program perkawinan, apalagi bila tidak terjadi kebuntingan (Feradis, 2010).

Kurangnya pengetahuan peternak tentang pengelolaan reproduksi khususnya mengenai deteksi birahi dan waktu yang tepat untuk mengawinkan akan mengakibatkan tingkat kebuntingan pada perkawinan pertama (Conception Rate) yang rendah, angka kawin perkebuntingan (Service per Conception) yang besar, jumlah waktu dari beranak sampai bunting (Days Open) kembali yang panjang, dan interval beranak (Kidding Interval) lebih panjang yang menyebabkan tingkat kelahiran cempe yang rendah.

Untuk memperoleh informasi secara tepat mungkin, perlu digunakan teknik-teknik penentuan fertilitas yang walaupun kurang sempurna, tetapi telah terbukti dapat memberi gambaran umum untuk penilaian pelaksanaan perkawinan sebagai dasar penentuan kebiksanaan selanjutnya. Beberapa parameter yang digunakan sebagai penilaian efisiensi reproduksi antara lain melalui Conception Rate (CR), Service per Conception (S/C), Days Open (DO), dan Kidding Interval (KI).

\section{Materi Dan Metode}

Penelitian ini dilaksanakan di Lembah Gogoniti Farm Desa Kemiri Gede Kecamatan Kesamben Kabupaten Blitar. Penelitian dilaksanakan mulai tanggal 1 sampai dengan 30 Juni 
2013. Materi yang digunakan dalam penelitian ini meliputi kambing Peranakan Etawa betina dengan kreteria masih produktif, mempunyai catatan lengkap dengan jumlah ternak 35 ekor yang dikawinkan dengan kawin alami.

Metode yang digunakan dalam penelitian ini adalah survei memakai data sekunder berupa kartu catatan kawin yang ada dipeternak. Pemilihan sampel ternak secara Purposive Sampling yaitu kambing Peranakan Etawa yang tidak dalam keadaan terganggu reproduksinya.Variabel Pengamatan yang diamati adalah Conception Rate (CR), Service Per Conception ( $S / C)$, Days Open (DO), dan Kidding Interval (KI). Analisis data yang diperoleh ditabulasikan, kemudian dihitung persentase atau rata-rata dan simpang bakunya yang selanjutnya akan analisis secara deskriptif.

\section{Hasil Pengamatan Dan Pembahasan}

Mempertahankan tingkatan fertilitas yang tinggi adalah dasar dan tujuan setiap program peternakan, kapan dan dimanapun. Makin banyak hewan betina yang kawin berulang (repeat breeders) akan sangat merugikan bagi pelaksana IB terutama bagi peternak (Feradis, 2010).

Evaluasi terhadap keberhasilan proses reproduksi dapat di nilai dari parameter efisiensi reproduksi. Untuk memperoleh produksi peternakan kambing yang baik dan bernilai ekonomis yang tinggi, perlu diperhatikan berbagai aspek penunjang baik yang bersifat dari kambing itu sendiri, maupun eksternal seperti lingkungan, kesehatan, nutrisi, dan faktor lainya. Aspek internal berhubungan dengan genetis kambing tersebut. Sifat genetis dapat dimanifestasikan dari kelakuan kelamin, dan sifatnya berbeda dari tergantung tipe dan ras ternak tersebut. Salah satu faktor yang harus diperhatikan untuk meningkatkan produksi ternak adalah proses reproduksi.

Menurut Susilawati, (2011) Efisiensi reproduksi semakin tinggi bilamana anak per kelahiran banyak dan jarak beranaknya pendek. Kambing yang memiliki efisiensi reproduksi tinggi adalah dalam tempo 2 tahun beranak 3 kali dengan jumlah anak per kelahiran 2 ekor, sehingga dalam 2 tahun menghasilakan anak 6 ekor.

Agar efisiensi rerpoduksi pada kambing tinggi, terdapat beberapa upaya yang perlu dilakukan :

- Dua bulan setelah menunjukkan birahi yang pertama maka kambing betina dapat di kawinkan dengan pejantan unggul, dapat menggunakan kawin alam maupun IB.

- Apabila terjadi kegagalan perkawinan ( menunjukan birahi kembali) maka sesegera mungkin dikawinkan kembali.

- Perlu pengawasan tanda-tanda birahi secara intensif, minimal 2 kali sehari saat memberi pakan.

- Dua atau tiga hari sebelum dikawinkan, sebaiknya diberi pakan yang berkualitas tinggi agar anak yang dihasilkan lebih dari satu.

- Selama kebuntingan perlu dijaga kualitas pakannya agar tidak terjadi keguguran.

- Perlu perhatian intensif pada saat induk akan beranak dan diupayakan tidak terjadi kematian saat beranak, sehingga perlu ditaruh pada tempat yang kering dan hangat.

- Diupayakan semua anak mendapat susu dari induknya. Apabila anak lebih dari 2 ekor, pada umumnya salah satunya perlu pemberian susu tambahan dari induk yang lain atau susu buatan.

- Setelah 40 hari, anak kambing perlu disapih. Pada saat tersebut anak sudah dapat makan sendiri dan uterus/rahim induknya sudah siap untuk bunting kembali.

- Dengan sistem ini diharapkan jarak beranak 8 bulan sehingga dalam waktu 2 tahun didapatkan 6 ekor anak bila per kelahirannya 2 anak (Susilawati, 2011). 
Deteksi kebuntingan dilakukan untuk mengetahui keberhasilan kebuntingan dari pelaksanaan perkawinan. Evaluasi kebuntingan dapat diketahui dengan menggunakan metode palpasi rektal sehingga dapat di ketahui angka conception rate (CR), service per conception $\mathrm{S} / \mathrm{C})$, days open (DO), dan kidding interval (KI).

\section{Conception Rate (CR)}

Conception Rate (CR) adalah suatu ukuran terbaik dalam penilaian hasil inseminasi yaitu presentasi hewan yang bunting pada inseminasi pertama Angka konsepsi ditentukan berdasarkan hasil diagnosa kebuntingan dalam waktu 40 - 60 hari sesudah inseminasi (Feradis, 2010). Nilai CR di Lembah Gogoniti Farm sebesar $85 \%$ yang artinya 35 ekor kambing yang pertama kali dilakukan perkawinan, $85 \%$ bunting atau 31 ekor kambing yang bunting. Dari nilai tersebut dapat disimpulkan bahwa angka CR di Gogoniti Farm baik, sesuai pendapat Achjadi, (2007) dalam Sulaksono, Sri dan Purnomo (2010) Nilai optimal CR pada kambing berkisar antara 50\% - 70\%. Partodiharjo, (1992) dalam Bambang, Sutama dan Budi, (1997) menambahkan bahwa angka konsepsi yang baik adalah apabila telah mencapai $60 \%$ atau lebih. Hal ini disebabkan oleh pakan yang diberikan oleh peternak sebagian besar berupa rumpur gajah, leguminosa dan pakan tambahan berupa konsentrat $3 \mathrm{~kg} /$ hari sehingga proses rerpoduksi bisa berjalan normal.

Angka konsepsi ditentukan oleh 3 faktor yaitu kesuburan pejantan, kesuburan betina dan teknik inseminasi. Pada perkawinan normal jarang di temukan suatu keadaan dimana hewan jantan dan betina mencapai kapasitas kesuburan $100 \%$. walaupun masing-masing mencapai tingkatan kesuburan $80 \%$ pengaruh kombinasinya menghasilkan angka konsepsi sebesar $64 \%$ (80 x 80) (Feradis, 2010).

\section{Service Per Conception (S/C)}

Service Per Conception ( $S / C$ ) adalah angka yang menunjukan berapa kali perkawinan dilakukan atau angka yang menunjukan jumlah semen yang digunakan untuk menghasilkan kebuntingan. Data tentang hasil penelitian berdasarkan pengamatan S/C dapat dilihat pada tabel 3 .

Tabel 3. Parameter Service Per Conception Kambing Peranakan Etawa pada Lembah Gogoniti Farm

\begin{tabular}{|c|c|c|}
\hline No & Umur (tahun) & S/C (\%) \\
\hline 1 & 2,5 & 1 \\
\hline 2 & 3 & 1 \\
\hline 3 & 4 & 1 \\
\hline 4 & 5 & 1,41 \\
\hline
\end{tabular}

Sumber: Data primer yang diolah (2013).

Dari tabel diatas dapat diketahui bahwa nilai S/C di Lembah Gogoniti Farm dihitung mulai dari umur 2,5 sampai 5 tahun adalah $1 \%, 1 \%, 1 \%$ dan $1,41 \%$ yang berarti dari 35 ekor kambing untuk terjadi suatu kebuntingan umur 2,5 tahun memerlukan 1 kali perkawinan, umur 3 tahun memerlukan 1 kali perkawinan, umur 4 tahun memerlukan 1 kali perkawinan dan umur 5 tahun memerlukan 1,41 perkawinan. Dari data tersebut dapat diketahui bahwa S/C dilokasi penelitian tersebut berada pada angka yang normal. Hal ini sesuai dengan pendapat Atabany (2000), dalam Sulaksono, Adi dan Purnama (2013) nilai S/C berkisar antara 1,0 sampai 2,0 kali.

Nilai S/C yang rendah menunjukan semakin tinggi fertilitas atau kesuburan hewanhewan betina pada peternakan tersebut, sebaliknya makin tinggi nilai S/C semakin rendah 
fertilitas atau kesuburan hewan betina tersebut (Feradis, 2010). Nilai S/C yang tinggi akan merugikan, karena mengakibatkan semakin banyak waktu yang dibutuhkan untuk mendapatkan kebuntingan, di samping itu juga banyak memerlukan tenaga dan biaya. Nilai S/C yang rendah menunjukkan bahwa rata-rata perkawinan untuk mendapatkan satu kebuntingan tinggi, sehingga biaya yang dikeluarkan semakin sedikit.

Menurut Kurniadi, (2009) dalam Sulaksono, Sri dan Purnomo, (2013) Tinggi rendahnya nilai service per conception juga dipengaruhi beberapa faktor. Faktor yang mempengaruhi tinggi rendahnya nilai $\mathrm{S} / \mathrm{C}$ adalah keterampilan inseminator dan waktu dalam melakukan inseminasi buatan pakan dan pemberian pakan, pengetahuan peternak mendeteksi birahi.

\section{Kidding Interval (KI)}

Kidding interval (KI) adalah jarak waku antara satu kelahiran dan kelahiran berikutnya (Hafez, 2008 dalam Susilawati dan Sri, 2010). Panjang pendeknya (KL) ini akan mempengaruhi tingkat produktivitas rerata kelompok kambing PE per tahun (Abdulgani, 1981 dalam Sulaksono, Sri dan Purnomo, 2013 ). Dari hasil analisis dapat dilihat di tabel.

Tabel 4. Parameter Kidding Interval Kambing Peranakan Etawa pada Lembah Gogoniti Farm

\begin{tabular}{|c|c|c|}
\hline No & Umur (tahun) & KI (bulan) \\
\hline 1 & 2,5 & 6,49 \\
\hline 2 & 3 & 6,56 \\
\hline 3 & 4 & 6,81 \\
\hline 4 & 5 & 7,04 \\
\hline
\end{tabular}

Sumber: Data primer yang diolah (2013).

Rara-rata nilai KI dihitung mulai dari umur 2,5 sampai 5 tahun adalah 6,49 6,56, 6,81 dan 7,04 hari. Dari hasil analisis tersebut menunjukan bahwa berada di angka yang normal. Hal ini sesuai dengan pendapat Lestari, (2009) dalam Sulaksono, Sri dan Purnomo (2013) menyatakan bahwa hampir semua kambing jarak waktu yang dibutuhkan untuk bunting kembali sekitar tiga bulan, sehingga nilai selang beranak kambing secara normal delapan bulan (240 hari).

Dari data diatas, dapat di ketahui bahwa semakin tua umur induk kambing akan menurun KI kambing tesebut. Menurut Hafez,(1993) dalam Hastono, Budi, Sianturi, Umi dan Sutama (1997) fertilitas kambing betina menurun disebabkan antara lain oleh cuaca panas, pakan berkualitas rendah, kegemukan badan, umur yang terlalu muda ataupun terlalu tua.

\section{Days open (DO)}

Days Open (DO) adalah banyaknya hari saat sesudah induk beranak sampai dengan bunting. Days Open pada seekor ternak dipengaruhi oleh beberapa faktor diantaranya IB yang mencakup teknik inseminasi, penggunaan semen berkualitas baik, kualitas estrus induk, kesehatan ternak, fertilitas induk dan manajemen yang meliputi recording, ketepatan dalam deteksi estrus dan nilai nutrisi yang memadai (Ax et al, 2008 dalam Susilawati dan Sri, 2010).

Data tentang hasil penelitian berdasarkan pengamatan DO dapat dilihat pada tabel.

Tabel 5. Parameter Days Open Kambing Peranakan Etawa pada Lembah Gogoniti Farm

\begin{tabular}{|c|c|c|}
\hline No & Umur (tahun) & DO (hari) \\
\hline 1 & 2,5 & 44 \\
\hline 2 & 3 & 46,8 \\
\hline 3 & 4 & 53,75 \\
\hline 4 & 5 & 60,5 \\
\hline
\end{tabular}

Sumber: Data primer yang diolah (2013). 
Rata-rata nilai lama waktu kosong (Days Open) induk kambing peranakan etawa di Lembah Gogoniti Farm yang diperoleh dari analisis di hitung mulai dari umur 2,5 sampai 5 tahun adalah 44, 46,8, 53,75 dan 60,5 hari. Berdasarkan hasil analisis menunjukan nilai lama waktu kosong dilokasi penelitian tersebut mempunyai nilai yang baik. Hal ini sesuai dengan pendapat Atabany (2001) dalam Sulaksono, Sri dan Purnomo (2010) melaporkan kambing PE di peternakan barokah di kawinkan kembali setelah melahirkan dengan jarak waktu rata - rata 64,20 hari dan rata- rata masa kosong 3,66 bulan (90 hari ).

Dari data-data diatas, DO dapat di ketahui bahwa, semakin tua umur kambing tersebut semakin menurun nilai DO. Ini sesuai pernyataan Vandeplassche, (1982) dalam Hastono, Budi, sianturi, Umi dan Sutama (1997) bahwa semakin tua umur kambing semakin panjang masa kosong dari kambing tersebut.

Menurut Sumadi, (2001) dalam Sulaksono, Sri dan Purnomo (2010) masa kosong (days open) adalah jangka waktu sejak kambing beranak sampai dikawinkan kembali dan terjadi kebuntingan. Panjang dan pendeknya masa kosong dipengaruhi oleh waktu perkawinan induk kambing setelah beranak tingkat kesuburan induk dan Service per Conception atau kegagalan dalam fertilitas. Hafez dan Jainudin (1993) dalam Susilawati dan Sri, (2010) menyatakan bahwa faktor lain yang berpengaruh terhadap panjangnya DO adalah peran inseminator, penanganan semen dan ketepatan waktu inseminasi.

\section{Kesimpulan Dan Saran \\ Kesimpulan}

Berdasarkan hasil penelitian dapat disimpulkan :

Untuk nilai Conception Rate (CR) 85\% di Lembah Gogoniti Farm bagus ini sesuai standard minimal 60\%. Untuk nilai Service Per Conception (S/C) Kambing Peranakan Etawa dilembah Gogoniti Farm umur 2,5 tahun 1 kali, umur 3 tahun 1 kali, umur 4 tahun 1 kali, dan umur 5 tahun 1,41 kali ini dalam keadaan normal sesuai dengan standard 1,0 - 2,0. Untuk nilai Kidding Interval (KI) Kambing Peranakan Etawa diLembah Gogoniti Farm umur 2,5 tahun 6,49 bulan, umur 3 tahun 6,56 bulan, umur 4 tahun 6,81 bulan, dan umur 5 tahun 7,04 bulan ini dalam keadaan normal sesuai dengan nilai optimum KI 9 bulan. Untuk nilai Days Open (DO) Kambing Peranakan Etawa di Lembah Gogoniti Farm umur 2,5 tahun 44 hari, umur 3 tahun 46,8 hari, umur 4 tahun 53,75 hari dan umur 5 tahun 60,5 hari ini dalam keadaan normal sesuai dengan nilai standard maksimal 90 hari..

\section{Saran}

Berdasarkan hasil penelitian ini disarankan para peternak Kambing Peranakan Etawa tidak hanya mengacu pada sistem Conception Rate (CR) saja. Sebaiknya harus memakai semua sistem di atas (CR, S/C, KI dan DO) sehingga nantinya akan mendapatkan hasil yang optimal.

\section{Daftar Pustaka}

Atabany, .I.K, Abdulgani,A. Sudono dan Mudikdyo : Permorma Produksi, Reproduksi dan Nilai Ekonomis Kambing Peranakan Etawa di Peternakan Barokah.http :// www. Respotitory.Ipb.ac.id. 25 Juli 2013.

Feradis. 2010. Bioteknologi Reproduksi pada Ternak. Bandung : Peterbit Alfabeta.

Hastono. Budiarsana. Sianturi. Adiati,U. dan Sutama,I-K. 1997. Pengaruh Umur Terhadap Kinerja Seksual Pada Kambing Peranakan Etawa. www. unikassel.de/unpress/online/frei/978-3-89958-074-7.volltext.frei.pdf. 25 Juli 2013

Ihsan,N.M. 2010. Ilmu Reproduksi Ternak Dasar Malang : UB Press. 
Muljana,W. 2006.Cara Beternak Kambing. Aneka Ilmu. Semarang.

Murtijo,B.A.1993.Kambing sebagai Ternak Potong dan Perah. Jogjakarta : Kanisius.

Roro.R,S. Bulgini.A._Cara Menentukan Umur Ternak. http:// awizarkawi. Wordpress.com/2012/08/10/ cara-menetukan-umur-ternak/. 10 Oktober 2013.

Sarwono, B.1990. Beternak Kambing Unggul. Jakarta : Penebar Suadaya.

Setiawan, T. Tanisius,A. 2003.Beternak Kambing Perah. Jakarta : Penebar Swadaya.

Suparman. 2007. Beternak Kambing. Jakarta : Azka Mulia Media.

Susilawati, T. 2011.Agribisnis Kambing. Malang : UB Press.

Sulaksono. A, Sri. S, Purnama. E.S. 2013. Penampilan Reproduksi (Service per Conception, Lama Kebuntingan dan Selang Beranak) Kambing Boerawa di Kecamatan Gedong Tataan dan Kecamatan Gisting. www. Jurnal Fb.Unila.ac.id/ Indek Php/ Jpt/ article/ view/ 39/ eoiz. 25 juli 2013.

Susilawati.T, Sri,W. 2010. Perbedaan Produktifitas Kambing Peranakan Etawa (PE) Antara Perkawinan Alam dan Perkawinan Inseminasi Buatan (IB) di Ampel Gading Kabupaten Malang. www. elibray.ub.ac.id/bitstream /1234567.../. 25 Juli 2013.

Stiadi.B, I-K.Sutama, I.G.M Budiarsana.1997. Efisiensi Reproduksi dan Produksi Kambing Peranakan Etawa pada Berbagai Tatalaksana Perkawinan. www. Pustaka. Litbang.deptan. go. Id/bptp I/ lengkap/ IPTAMA/ Realitek/ Jilmuter/ 2497_4. Pdf. 25 Juli 2013.

Theford, T. R. 1984.Penuntun Kesehatan Ternak Kambing. Bogor : Badan Penelitian Penyakit Hewan. 